Open Access

\title{
Instilling innovativeness, building character, and enforcing camaraderie through interest-driven challenge-based learning approach
}

Mas Nida Md. Khambario

$\overline{\text { Correspondence: khamasnida@upm. }}$ edu.my

Department of Foundation of Education, Faculty of Educational Studies, Universiti Putra Malaysia, 43400 Serdang, Selangor, Malaysia

\begin{abstract}
This study aims to identify how student teachers were impacted by an interestdriven challenge-based instructional design of an Educational Technology course over three semesters. The instructional design of this course was foregrounded by the Interest-Driven Creator Theory, anchoring on the two out of three concepts, namely Interest and Creation. Over the course of 14 weeks, the learning activities in each class meeting started by applying the Interest Loop. This was done by inviting students to participate in bite-sized challenges, at the same time making sure that students can extend the newly constructed knowledge from the activities to their final project. The objective of such design was to let students learn by doing or completing the weekly challenges given to them during class. Then, the students were guided to complete their final project through a series of workshops and personal group consultation with the course instructor. A focus-group discussion was conducted to gather data from the students over the course of three semesters, centering on answering the question of: How does an interest-driven challengebased framework for learning design of an Educational Technology course impact learners? Interviews were conducted qualitatively, and the findings of the analysis that emerged were (i) instilling innovativeness, (ii) building character, and (iii) enforcing camaraderie. These findings suggests that a mesh-up between the interest-driven creator theory and challenge-based learning framework, then named as InDeC framework for learning design, could furnish learners with skills that are beyond those targeted in the course outcome. Among others, learners' heutagogical skills can be improved when they are given the opportunity to realize their capacities and stretch their capabilities. Implicitly, this research may benefit instructors in their emerging responsibility of producing and readifying learners for future demands and challenges.
\end{abstract}

Keywords: Interest-driven, Challenge-based learning, Educational technology, Instructional design, Innovativeness, Building character, Enforcing camaraderie, Student teachers 


\section{Introduction}

The advent of personal computing, especially smartphones, and the Internet, have created new opportunities for the learners to have access to information and turned it into a culture today. Because of that, most of the learners nowadays are better at managing their own acquisition of knowledge through informal learning (Apple Inc. 2010). Their constant interaction with technologies and the Internet has become ordinary to their lives. These learners are more dynamic, adaptive to new things, and most importantly, like challenges and want to be challenged. Therefore, modifying the classroom learning environment is crucial to address the needs of today's learners, as well as preserve a positive classroom climate (Epstein et al. 2008). Clearly, teaching endeavors have changed exponentially in the past decade-learners are required to have more autonomy over their learning, thus pedagogical paradigm ensues.

The Malaysian Education Ministry has started charting waves of transformation to accelerate improvements in Higher Education instructions through technologyenabled innovations so as to democratize access to education and offer more personalized learning experience, thus creating a new generation of Malaysian students who excel globally in a competitive environment (Ministry of Education Malayia 2015). Furthermore, the Malaysian Education Minister in his mandate emphasized that university graduates are expected to become public intellectuals who are able to solve societal problems (Ministry of Education Malaysia 2019). Given this scenario, instructors need to become agile so as to be readily and continuously adaptable with pedagogical changes and innovations to cater the needs of today's learners without compromising the quality of knowledge provided to them.

At Universiti Putra Malaysia, several initiatives have been carried out to transpire creativity and innovation in teaching and learning. These are in line with the university's aspiration to produce quality, future ready graduates with added value and global status, thereby improving their competitiveness in the job market (Universiti Putra Malaysia 2014). In response to these aspirations, this action research was carried out to explore the possibilities of benefits of the mesh-up between the interest-driven creator theory and challenge-based learning framework as a learning design to facilitate the learning of the Educational Technology course. This course is a compulsory course to be taken by all student teachers undergoing teacher training degree at the university. Most importantly, this research aimed at understanding the impact of this learning design on learners. Therefore, the research question that drove this study was: "How does an interest-driven challenge-based framework for learning design of an Educational Technology course impact learners?"

\section{The interest-driven challenge-based learning as a conceptual framework for learning design}

In order to facilitate swift discussion on the conceptual framework of an interestdriven challenge-based learning $(\mathrm{InDeC})$, the discussion shall begin with foregrounding the challenge-based learning (CBL) framework. Challenge-based learning encourages learners to be actively engaged in learning through collaborative hands 
on activities, by leveraging common technologies they use in their daily lives to solve real-world problems (Apple Inc. 2010). These are meant to augment learners to develop deeper knowledge of the subjects under study and extend it to a larger crowd.

The CBL framework, as developed by Apple Inc. (2010), consists of five main stages of implementation, as follows:

\section{Stage 1: big idea and essential questions}

Learners are given a premise of current issues related to them, that they can help solve. The teacher should give questions that would guide them in finding solutions to the problem. At the same time, learners are encouraged to leverage commonly used technology in their tasks to solve the problem.

\section{Stage 2: foundation and challenges}

At this stage, learners formulate questions that can help them solve the issue. This step works best with learners working in groups and collaborate with each other. The instructor should remind the learners that they have the options to use multi resources to devise their plan for activities and resources.

\section{Stage 3: solution}

The learners should arrive at a solution plan by now and have a solid foundation to begin prototyping or experimenting with their solutions. Several research and documentation are done at this stage.

\section{Stage 4: implementation}

Learners have implemented their solution plan and assess what worked or what didn't work from the plan. At this point, learners will have to decide what they want to assess and determine whether they had progressed in addressing the challenge.

\section{Stage 5: assessment}

Throughout the whole project planning and implementation, learners document their work in the form of audio visuals and share their work in a public domain, highlighting on the process done, how it was implemented, and their own reflections. The institution is encouraged to organize a public event as an avenue for learners to share and celebrate their efforts.

Although the challenge-based learning framework is comprehensive to be used as a guideline, through six semesters of implementing it, I found that details in designing learning is rather linear. Therefore, a much meaningful and practical implementation of the CBL can be beneficial through its mesh-up with interestdriven creator (IDC) theory that can offer iterative and cyclical practices. Both theory and framework also complement and reciprocate one another at certain stages. Further discussion and visualization are provided in the forthcoming paragraphs.

The IDC theory puts forth learner's interest as a driving factor for an enjoyable and effective learning journey (Chan et al. 2018). This theory is a contemporary learning 
theory that suggests the use of appropriate instructional design and technological support could help learners experience a personalized learning that is tuned to their interest by vigorous contextual design and nurturing. In addition to that, a well-thought learning activities can also be developed as interest-driven creation activities. The deeply rooted presumptions of this theory is that learning is a process that is composed of three anchoring concepts, namely interest, creation, and habit. However, for this research, only two anchors were deployed, namely interest and creation.

According to Chan et al. (2018), interest in learning can be piqued through three cyclical events, namely triggering, immersing, and extending. The first component, triggering, is the stage where pre-cursor activities are conducted to induce interest for the coming learning activities. This is meant to evoke learners' intellectual curiosity and promote the passion to learn, as outlined in the guide by the England Department for Education (2011) through a well-structured lesson. To evoke curiosity, stage 1 (Big Idea and Essential Questions) of the CBL framework can be applied by giving learners a premise of current issues related to them, that they can help solve. The instructor shall give questions that would guide learners in finding solutions to the problem. At the same time, learners are encouraged to leverage commonly used technology in their tasks to solve the problem. The second component, immersing, pertains to designing activities for learning that requires full participation and attention of learners. Creating a flow of experience may be beneficial to learners' engagement (Wilhelm and Wilhelm 2010). This can be done by applying stage 2 (Foundation and Challenge) of CBL that suggests learners take the accountability to solve the challenges collaboratively and collectively. At this stage, learners shall devise plans to overcome the challenges, thus making them more invested in the learning process-exercising and stretching their abilities and skills-that leads to learning satisfaction.

Extending, the final component of the interest loop, refers to post-activities that are designed to provide opportunity for learners to apply the newly constructed knowledge in a similar or different context and nature. Stage 3 (Solution) of the CBL framework comes in handy in detailing how the solid plans formed at the previous stage can be concretized and applied onto a real situation, thus broadening learner's knowledge and experience. This stage continues to the next loop.

To get a much comprehensive learning design at a macro level, the creation loop can be used in the learning design. Chan et al. (2018) emphasized that learning and creating are parallel to one another. This loop comprises three components as well, namely imitating, combining, and staging. Imitating concerns on learner's ability to capture information through observation, and emulate it. Several research and documentation are done through modeling, which is in line with stage 3 (Solution) of the CBL framework. This involves learners mining for information and examples from multi-resources that can be considered for adoption and adaptation for their own project. Next, combining involves activities where learners synthesize and form innovative projects from ideas that they have come across at the previous stage. This means that stage 4 (Implementation) of the CBL framework is employed, where learners execute their solution plan and assess what worked or what did not work from the plan. Learners will identify and self-determine how 
they have progressed and later address the challenges. Finally, staging, which is the final component of the creation loop, is an avenue for learners to present and share their projects with people outside of their classroom. This aligns with stage 5 (Assessment) in CBL framework which requires learners to provide multimodal evidence of their work at a place accessible to the public, detailing on reflective thinking process. In addition to that, the framework recommends the institution to coordinate public events as an appreciation platform to celebrate learners' efforts. These activities complete the creation loop.

The visualization of the aforementioned learning design can be understood from Fig. 1. This figure illustrates the interest-driven challenge-based learning (InDeC) framework. Note how the stages of the CBL framework resonate the components of the interest loop and the creation loop. Solution, which is stage 3 of the CBL framework, appears in both extending component (final component of the interest loop) and staging component (first component of the creation loop). This suggests that a learning design that employs both anchors namely interest and creation loop, enables learners to further extend their knowledge that may lead to constructing a much concretized learning experience. It is also worth noting that both IDC theory and CBL framework complement and reciprocate one another.

\section{Contextual background: application of InDeC framework in the Educational Technology course}

The subsequent sections will then foreground the instructional design of an Educational Technology undergraduate coursework which were conducted over the course of 14 weeks, based on the InDeC framework. Through this course, learners were required to produce an instructional media that suits the twentyfirst century learning challenges and demands, as their final project (course outcome). In addition to that, learners must write an individual ePortfolio to reflect

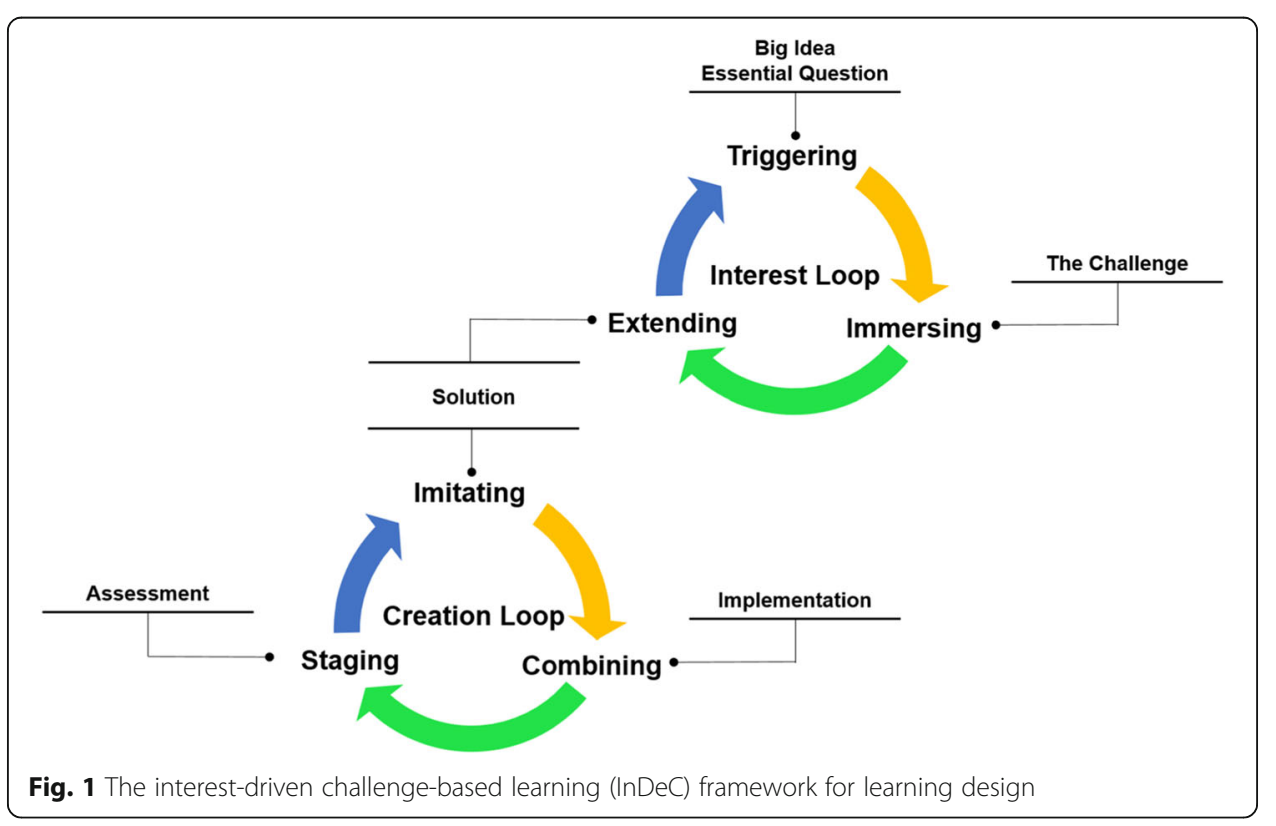


on their learning and do a project presentation. This coursework needed to be done in a group of four members.

\section{Triggering component (big idea and essential questions)}

On the first day of the semester, as the course instructor, I started the lecture by posting two questions related to the Big Idea in the teaching context for the learners to reflect on (i) "Why do you want to become a teacher?" and (ii) "How do you want to be remembered as a teacher?" And then, I shared my teaching philosophy and got my learners to come up with their own teaching philosophy as a means to set their thinking as a future teacher. I believe this is an important part of teaching student teachers, which is to get them ready for school and the challenges they are expected to embrace.

In the following weeks, learners were triggered with several ideas meant to let them come up with the Big Idea for their final project, from which they considered the topic: gamification in education-a topic that serves to address the needs of twenty-first century teaching challenges, and has several meanings to the learners who were student teachers at the time this research was conducted. Learners were exposed to a number of examples of traditional and practical gamifications in life, but not how gamification is applied in education. This was meant as an information gap to let learners explore (Chan et al. 2018) how gamification can be applied in education.

In the first 3 weeks into the semester, I guided the learners to form Essential Questions that could help them create an instructional media that could serve the learning and challenges of twenty-first century education. This were done through a Socratic questioning technique, where I asked some guiding questions, to trigger learners to think deeper and come up with their own questions. Some of the questions the learners came up with were:

- How can games be embedded in education?

- How does game speak to the needs of twenty-first century challenges and needs in education?

- What kind of games should be produced?

- What kind of content is suitable to be gamified?

- How do I design a gamified instruction?

- What learning theories can be applied in the instructional design for gamification?

Through, and by the end of the Essential Questions process, learners had become more invested with the desire to bridge the information gap and were pre-immersed in the final project. The learners were then led to a series of challenges to maintain a smooth flow of immersion.

Immersing component (the challenge)

Following the Essential Questions, a series of challenges through guided questions, activities, and resources were formulated as a foundation to help learners find the 
solution. These were done through several activities designed for the next 7 weeks of the semester including weekly consultation during lab sessions, weekly lecture activities, seminar, and workshops.

- Weekly challenges during lecture were also conducted by the course instructor. Every week during class, the learning activities started by applying the Interest Loop in a micro level. This was done by inviting students to participate in the weekly bite-sized challenges, at the same time making sure that students can extend the input from the activities to their final project. The objective of such design was to let students learn by doing or completing the weekly challenges given to them during class. Among the challenges learners had to do collaboratively with their group mates were (i) designing a lesson introduction in five minutes using limited resources (Instructional Design), (ii) producing drawing based on a complex text (Instructional Media), (iii) participating in an explore race quiz (Gamification), and (iv) criticizing and producing infographics (Visual Message Design). These were the essential topics that would furnish the learners with the related knowledge to complete their final project.

- Seminar in emerging technologies, pedagogies, and theories were conducted to furnish learners with important relevant information that can help them progress with their final project. Three speakers, each of them who are specialized in emerging technologies and immersive learning, IDC theory, and practical gamification, were invited to talk at this seminar.

- Workshop on augmented reality were conducted to challenge learners to create their own augmented reality for learning purposes using their own smartphones and a free commercialized mobile apps. This was meant to let the learners (or student teachers) know that a commonly used technology can be practicalized into their own teaching.

- Workshop on developing educational board games were conducted, and a consultant was appointed to share his experiences in developing educational board games that is now commercialized. At this workshop, learners get to pitch their ideas on their final project to the consultant, as well as get a personal consultation regarding their final project.

- Workshop on copyrights and product pitching were conducted by two experts that focused on the importance to get the intellectual property protected, and how to get people attracted to a product or an innovation. This workshop was conducted in preparation for the product presentation (final component in the coursework).

The final workshop was designed to help learners identify the solution to their questions in developing a gamified instruction for their final project. Learners had come to a consensus and firm decision to develop board games as a mean to integrate gamification in education. Thus, during the final workshop, learners were encouraged to bring their drafts and sketches of board games design (from which they have consulted the course instructor weekly during lab sessions) to prepare it for the development process. 


\section{Extending component (solution)}

In order to let learners extend their theoretical knowledge, more learning activities were designed toward garnering more information to help them close the information gap.

- Innovation exhibition in conjunction with educator's day. Learners were encouraged to visit innovation exhibitions by researchers in the university at the Educator's Day event. This was meant as an avenue for the learners to explore the types of innovations other people had created and get to generate a firmer solution to their ideas for the final project.

- Workshop on design thinking, innovation, and mock-up development were conducted to instill design thinking among the learners, and help them come up with a mock-up of their projects. A team of two consultants and five facilitators from the Industrial Design background were appointed for this workshop. Through activities in this workshop, learners were being loosened up with fun learning activities so that they can prepare their minds for design thinking challenges. Also, at this workshop, learners came with drafts and sketches of their board games. As they progress throughout the workshop, learners were able to identify possible solutions as to how they should proceed with their board games. Their drafts and sketch-ups were then further developed and detailed during the workshop-translated into physical forms. About 50\% of their final projects mock-ups were completed at this workshop.

By the end of the Interest Loop, learners were able to extend the knowledge they gained from the challenges and translate it into their final project. Through these challenges, learners were observed as having a firmer objective for their final project and stability in their decisions to complete the challenge of the tasks given to them. Through weekly consultation with the learners, I found that learners had shown an invested interest in completing their final project, more energized and enthusiastic in talking about and presenting the progress of their final project, showed a sense of ownership over what they have created together, and an aroused atmosphere of competitiveness among the groups of learners. These resonates with the assumptions of IDC theory that learners will enjoy and endeavor to learn and will develop necessary twenty-first century skills that can prepare them for lifelong learning, and will be able to explore and develop their potential and talents (Chan et al. 2018).

\section{Imitating component (solution)}

Following the final workshop on Design thinking, innovation, and mock-up development, learners were observed as having a clearer idea on how their final project (which is the board game) should look like and the audience they can serve. As such, their deeper understanding of the knowledge were reflected in their mock-ups as they are being much able to adopt and imitate necessary elements of games and gamification from materials available in the marketplace and online resources, into their own project. 


\section{Combining component (implementation)}

The final 4 weeks of the semester were dedicated for the learners to combine their existing and new knowledge, ideas, and materials to create the final product into a real prototype. At this stage, learners visit and re-visit their design, and concretize their final project through a series of input in the forms of personal consultations with the course instructor (each group spent approximately 1 to $2 \mathrm{~h}$ per week with the instructor) and test-runs with their classmates.

\section{Staging component (assessment)}

Learners also prepare their projects to be presented at the Innovation Showcase, an innovation competition event inaugurated by the course instructor as an avenue for learners to stage and introduce their products to the public. Undergraduate and postgraduate students, academics, and non-academic staffs in the university, teachers, and communities around the university were invited to the event. At this competition, learners were given the opportunity to reveal their project by showcasing a poster at their dedicated booth and demonstrating their board games to the booth visitors. Two judges who were experts of innovation were invited to evaluate and give feedback to their project. Four out of eight group of learners from the Educational Technology course bagged a gold medal, two silver medals, and a bronze medal in this competition. However, these medals were not counted in their carry marks for their coursework.

Throughout the semester, learners were required to write their weekly reflections regarding the progress of their project and their learning process for this course in the form of ePortfolio. Learners were given the flexibility to compose their own ePortfolio using any electronic platform available on the web, and share the URL to the course instructor for evaluation at the end of the semester (after Innovation Showcase). This was meant for (i) the learners to reflect on their work and share on how they arrived at the solution they proposed and implemented, and (ii) the instructor to better understand learners and their thinking process for continual teaching and learning designed to improve quality.

\section{Methods}

A qualitative action research was carried out for the purpose of answering the question, "How does an interest-driven challenge-based framework for learning design of an Educational Technology course impact learners?" Because this research is considered as my own "classroom research," action research is deemed the most suitable as it allows for research to be set within a specific context (which in this research, was the classroom) that involves continuous modification throughout the semester (Koshy 2005; Maree 2007; Ryan 2013). Cross (1986) suggested that a classroom research plays a vital role in optimizing student learning, by which instructors consciously reflect on their teaching goals and pedagogies as a mean to build a supportive student learning environment, in a spiralling process, to refine and explore new ways of efficient teaching. Since this is a qualitative action research and was tailored toward improving my own instructional practices, the results of this research may not be generalized, but can be adapted and adopted by instructors who may have similar situations as mine. 
This research was carried out over the course of two semesters with undergraduate students enrolled in the Educational Technology course, a compulsory course to be taken by all student teachers. Using the spiraling action research framework proposed by Kemmis and McTaggart (2000), two cycles of research were employed over a duration of two semesters, involving 24 student teachers in the first semester, and 54 student teachers in the second semester. The first semester involves the planning, acting and observing, and reflecting on the teaching practice. In the second semester, a revised plan were carried out, acted and observed, and reflected on. Data were collected in between the first and second semester involving the first cohort of students, and were collected again at the end of the second semester, involving the second cohort of students.

An initial descriptive open-ended qualitative survey were carried out among all student teachers enrolled in the Educational Technology course during the end of the first and second semester. From the survey, the data collected were preliminarily analyzed by applying the grounded theory technique which involves open-coding and memoing, and constantly comparing the codes with one another to arrive at themes (Charmaz 2015). Initial findings point to themes that were rather vague and quite superficial such as fun and enjoyable learning, increased collaboration, and motivating. This warrants for a deeper understanding of the learners, thus, a focus group discussion were employed at the end of the second semester.

Focus group discussion (FGD) was then employed among learners who voluntarily were willing to become a research participant. Students were invited to participate in the interview, and five out of 88 students signed up as participants. Although only five students participated in the FGD, this interactive nature of this method was able to generate a wide range of data within a short period of time as compared to a series of single interviews (Fern 1982; Hennink 2014). In addition to that, the dynamics of the group discussion have led to a broader and deeper, as well as different type of data that may not be accessible through individual interviews. For instance, during the FGD, the students were able to listen and respond to each other, and refined their own views in light of what they have heard. This had thus increased the clarity, depth, and detail of the discussion (Hennink 2014). For the FGD, four of them were males and one was a female student. These student participants came from different project groups. They had given consent for the information shared to be used, but their identity and personal information will remain confidential and only pseudonyms were used to address these participants as a human-safeguarding measure.

Open-ended semi-structured interview questions were formulated based on the conceptual framework (Fig. 1) and the interview protocol were altered throughout the second semester to reflect the emergent ideas through the preliminary analysis and on-going teaching and learning process. Other than the interview protocol, during the FGD, I have also utilized prompts as an interview technique to get the group to be more interactive and responsive to one another. The audio-recorded interview session lasted for approximately $105 \mathrm{~min}$. The audio were then transcribed and any local slang that were used were translated to the English language. 
A back-to-back translation method was employed to ensure the meanings were not lost in translation.

The data were initially analyzed using open-coding and memoing, and were later re-coded (where appropriate) as I read and re-read the transcript. The constant-comparative methods were applied as a means to arrive at analytic distinctions (Glaser and Strauss 1967; Charmaz 2015) by comparing data to data, to find similarities and differences. After getting familiar with the data and a list of significant codes were produced from the initial coding, a focusedcoding technique was applied to sift through the data in order to arrive at the adequacy of the codes (Charmaz 2015). To increase the trustworthiness and authenticity of the data, member checking was carried out by discussing the findings with the participants to gain their validation. This step helped in improving the credibility and transferability of this research (Denzin and Lincoln 2017).

In addition to that, the preliminary themes that emerged, which were fun and enjoyable learning, increased collaboration, and motivating-were revisited and referred to again as a mean to find deeper meaning and emerging themes that could better characterize them. As such, three significant themes emerged from the analysis process, namely instilling innovativeness, (ii) character building, and (iii) enforced camaraderie. Findings are presented descriptively in the following section.

\section{Results and discussion}

The findings that emerged from the analysis found that the challenge-based instructional design of the Educational Technology course for student teachers have augmented in (i) instilling innovativeness, (ii) character building, and (iii) enforced camaraderie among learners.

(i) Instilling innovativeness

The first theme that emerged from the findings was instilling innovativeness, where learners got the opportunity to browse and shop-talk ideas and leverage technology they commonly used to produce a customized educational board game. Two participants had expressed their anxiousness on creativity when they first learnt about the coursework for the Educational Technology course.

When we first talked about gamification and our project, I was like, "Oh man this was going to be tough," because I do not know how to develop games - although it was not going to be fully digital. But we have to embed augmented realities as well and to make it educational was another challenge. But as we progressed through the semester until the very end and our project worked - the motor moved our gears I told myself, "Not bad!" I never thought that I could be this creative and pull this off. We were so used to writing reports as assignments, but this course, we had to create something, a product of our own, and that was awesome.

(Adrian)

I heard the word game and I immediately loved it! I have no idea what it was going to turn out like, but I know it has to be something creative and we 
have to be creative, you know, thinking creatively and critically. And yes, it had definitely turned me into a creative person when we did our project.

\section{(Norman)}

The aforementioned remarks are evidence that the $\mathrm{InDeC}$ framework for the Educational Technology learning design was able to sustain learners' interests in the course, help them discover their abilities to produce creative projects, although the learners perceived it as rather comprehensive and intimidating in the beginning. However, the activities designed through the InDeC framework gives opportunities for learners to browse and shop-talk ideas through modelling on other people's work or online resources. This is consistent with the extending component in the Interest Loop and the imitating component in the Creation Loop where learners look for solutions and devise a plan for implementation.

\section{Browse and shop-talk ideas}

Learners have mentioned that the series of workshops and events that they have participated throughout the semester had given them the chance to generate ideas, broaden their mindset, and translate their experience into their project.

We talked to other groups, asking them "How do you do your project? How is it doing?" and what not. We learned about their projects, we didn't even have thought on doing what they have thought of doing. Then we improvise our work. I think this has helped us in one way or another in developing our project.

\section{(Sharon-Lee)}

I got triggered when I looked at the exhibitions during the Educators' Day. We tried a board game during the exhibition and theirs was on Medic Education ... and so I thought, "Oh wow this is interesting, I think we can apply this idea on our project."

(Hazry)

Yes we adapted some work. We got ideas from there (exhibition) and when we got back, we changed our design for snake-and-ladder into something craftier.

(Adrian)

... from the Design Thinking workshop, we learned about how we can specifically finish-up our gamification project. I think the avenue provided by the course instructor, this really helped me to have a sustained interest in completing our work.

(Benjamin) 
The Design Thinking workshop had an imprinted effect on me because we were taught on how 3D models were made ... we also had the chance to talk with the consultant during the Question and Answer session. And he is from the Faculty of Design and Architecture, which is awesome.

(Norman)

These interview excerpts imply that learners' participations in exhibition and workshops had increased their curiosity, at the same time, boosted their confidence when they were aware that they could almost find the "missing piece" of the information gap casted upon them. Learners were somewhat starting to get immersed into the learning process as they have an aim to accomplish. Through invested involvement in the project through activities design using the InDeC framework, new ideas and fresh thinking can take root-thus further equipping learners with competencies they will need in the future ever-challenging world (Johnson et al. 2009).

\section{Leveraging technology}

In conduit with the aforementioned findings, Poth (2019) also suggested that innovative learning experience can be provided to learners by leveraging technologies in teaching and learning. It can offer students more personalized opportunities for peer-to-peer interaction and content engagement. This is evident in the findings where learners narrated impressiveness in their ability to use technologies for this course, either during lecture or for their project.

We shared with the students [exhibitors at Educators' Day] that we were developing our board games at that time, and that we were also going to develop a game inspired by the Monopoly, just like theirs. It's just that ours are going to embed Augmented Reality elements in our games. So the students were like, "Wow, how do you develop augmented reality? Isn't it difficult to create one?" But to us, it was not difficult at all because we had learned in the augmented reality workshop on how to create them.

(Sharon-Lee)

The consistent use of devices, usually smartphones, has increased my self-efficacy on anything related to the use of technology. After the semester ends, I was still thinking on the possibilities of games I can create using gamification and technology for my own area of study.

(Norman)

For the Explorace Game we played during class, I think that was great. We must have good companionship for the race or else you're going to finish late ... at each stations, we have to check-in. During that time, we were all immersed in an IT environment. Because we had to scan the augmented reality using our phones, check-in 
by posting pictures with our partner, and contacted other groups to ask for the locations of the stations and clues.

\section{(Sharon-Lee)}

These findings are in consistent with Poth (2019) who claimed that an improved communication among learners can be achieved when the right, especially commonly used technology, is optimized. The practicality of $\mathrm{InDeC}$ framework is particularly in line with the spirit of challenge-based learning where learners work collaboratively with peers, teachers, and distant colleagues via the Internet, leveraging on technologies they used in their daily lives to solve real problems (Apple Inc. 2010). Although the above evidence were cited from different activities outlined in the InDeC framework, they all pointed to the same theme, namely learners' increased skills in leveraging technology. It is also worth noting that the activities from the InDeC framework has a lasting impact on one of the learners when he mentioned that he kept on thinking about possibilities of creating more games even after the course has ended.

\section{(ii) Character building}

The second theme that emerged from the findings was character building. Learners mentioned that the instructional design of this course has helped them in improving their soft-skills and resiliency toward challenges. One of the seven key skills set for twenty-first century (Moylan 2008), which is communication skill and information fluency, is evident as narrated below:

My communication skills with my coursemates have improved. We seldom talk this much. But as we were preparing for the Innovation Showcase, we really talked a lot to make sure our project will turn out as how it was supposed to be. During class and after class, we discussed about our projects. Ideas kept flowing.

\section{(Sharon-Lee)}

Greater communication and team work occurred during the final days leading to their project presentation at the end of the semester, where communication and problem-solving continuously and rapidly happened. The teams faced challenges and setbacks along the way, and this had forced them to visit, re-visit, and modify their plans to overcome the problems. Learners were very much engaged and invested in their projects, especially when the final presentation were designed as an open presentation to the public (staging component).

The Innovation Showcase had really stimulated my eagerness, because I know we were going to present our work to outsiders, not only to our classmates or to our own instructor. Communication, teamwork and critical thinking-all of these-and problem solving. As we came closer to the Innovation Showcase day, 
ad-hoc things happen every now and then. We had to think real fast to solve our problems. Sometimes our game didn't work, our plan didn't turn out as how we had hoped it to be.

\section{(Norman)}

It was also evident among the learners that the design of the Educational Technology course had stretched their skills and tested their resiliency, especially the final staging during the Innovation Showcase event where learners experienced challenges in a multitude of forms.

Days leading to the Innovation Showcase, I started to feel really anxious. But we had to devise our plan really careful, there is no room for mistake because it was not going to be the course instructor who was going to evaluate our work, but judges from other faculties.

(Hazry)

Our plans keep changing. It can change in a blink of an eye. We have to be very very very flexible.

(Benjamin)

Even during the day of the presentation, the learners were able to construct iterative knowledge and skills as they observe how others presented their work, and applied the observation on their own presentation.

We had the opportunity to improve our communication skills when we observed how others pitched their projects to the judges [during Innovation Showcase]. If the project presentation were to be done in class, I believe most of us would present it rather differently. But for Innovation Showcase, everyone was like, more serious and composed.

\section{(Norman)}

The above excerpt is in congruent with Apple Inc. (2010) that proposed learners' interaction with peers or teachers (other than classmates and own instructor) is the most beneficial and enjoyable aspect of learning as it promotes professional growth and development. On another note, learners had narrated that weekly consultation and project check-ins with the course instructor had developed their resiliency toward challenges, critics and comments.

I remember we were about to present our progress to you and something on our board game didn't turn out as how we want it. So we had to keep on thinking about having back-up plans. Like, "What can we do if the course instructor would give us another advise and this had to change?"

(Benjamin) 
My take away for this course is that I have learned to think about alternatives and opportunities. There are many ways to achieve our objectives, maybe it was not meant to be straight forward, but we can still achieve it. We can't be too rigid in doing things.

(Hazry)

I am the kind of person who likes to plan ... I will make sure what I have planned will be done. But this course has changed my perspectives-there were a lot of unexpected changes, sometimes what I have planned didn't work. I was frustrated and thought that I didn't properly plan my work. But I think I am more acceptable to changes now, because when I changed some of my plans, the project turned out to be better than I thought. And that was very satisfying.

\section{(Adrian)}

It was evident from the findings that learners were able to embrace criticism and bounce-back, although they had to change their plans. These findings are in congruent with Yang et al. (2018) who suggested that innovativeness could increase courage and resilience levels among learners. These aligns with IDC theory which hypothesizes that learners will become life-long learners when they are allowed to enjoy and gain a sense of achievement in their life (Chan et al. 2018). Furthermore, learners will better develop their twenty-first century skills through the Educational Technology course through the implementation of InDeC framework.

\section{(iii) Enforced camaraderie}

The third theme that emerged from the findings were enforced camaraderie, where learners noticed a heightened positive vibes revolving around them and sense of camaraderie among themselves. They reported that they are free to share ideas and argue, instead of fight, with one another. Although there were ups and downs, they managed to sustain a good group synergy. The interview excerpt below shows an example how learners exercise core skills that leads to overall personality development (Balaji and Somashekar 2009), such as diplomacy, conflict management skills, negotiation and persuasion, flexibility, and orientation towards goal.

[my mood] was down a few times. Sometimes I thought I got this, the other moment I felt I can't continue with the project. Our group members have different ideas, so it was quite tough to come to a consensus, you know, to get everybody to agree with the project. And then sometimes our ideas worked, and sometimes they didn't work. But we embraced our differences and finally get to finish it [the project].

(Adrian)

"Competitiveness" was in the air. When other groups were demonstrating their project to the instructor, we were like "Wow." We looked into another direction and 
there was another group sharing about their work to others, and we were in awe. We kept on telling ourselves that we need to do something outstanding and get it done by the end of our timeline.

\section{(Hazry)}

Teamwork had occurred at a greater level, where learners expressed that they were not only motivating one another within their team, but they were also proud of the other team's accomplishments during the Innovation Showcase event. This shows that learners have developed maturity through the activities that were designed for them through InDeC framework.

We gave words of encouragements to one another, and that kept us moving. Whenever anyone of us throws an idea on the table, we would praise them. We kept on checking on one another and that gave us the spirit we needed.

\section{(Sharon-Lee)}

The highlight during the Innovation Showcase was the award giving ceremony. I didn't win anything but I was very proud of my coursemates. Some of them bagged gold medals, some silver and some bronze. I was anticipating for our team to be announced as one of the winners, but we didn't get a medal. Nevertheless, it was a proud moment for me to see my coursemates got on the stage and take their medals.

\section{(Hazry)}

These findings clearly show that learners were getting more comfortable to express themselves while practicing diplomacy and conflict management skills with their team mates. From these evidences, the $\mathrm{InDeC}$ framework appeared to encourage learners to be more actively collaborative, enthusiastic, and have an invested motivation in completing their projects especially when they were nudged by competitors from other groups. Similar experience was found in the studies by Moylan (2008) and Yang et al. (2018) among learners who participated in a team work project activities.

\section{Conclusion}

This study suggests that the InDeC framework for learning design could enhance the implementation of the Educational Technology coursework. From the findings garnered, I believe that the combination of both IDC theory and the challenge-based learning framework had produced greater outcomes, as compared to implementing each theory and framework individually. The learning design framework took heed of the suggestion by Chan et al. (2018) that it is crucial that students' interest on the lesson be piqued even before the start of the lesson. With this in mind, the interestdriven creator theory was applied at the learning design level before the Educational Technology course commenced for the semester. It is known that IDC theory posits that technology enhanced lessons that are designed using its framework will trigger students' interest in learning and immerse them in the creation process and this in turn 
strengthen their habits of creation. Capitalizing on this theory and overlaying it with the challenge-based learning framework, thus InDeC framework ensues, it appears that I was able to enhance learners' heutagogial and life-long learning skills to some extent. With the implementation of InDeC, I was also able to put them into an autonomous position of their own learning, turn them into active participants in class activities, and augment the construction of new knowledge, competencies, and skills on their own (Johnson et al. 2009; Apple Inc. 2010; Freeman et al. 2014; Carr et al. 2015).

Nevertheless, the important take-away from this research is that the implementation of InDeC framework for learning design had instilled innovativeness among learners, built their character by furnishing them with appropriate skills in readifying them for the future world, and enforced camaraderie among them. As such, learners were able to practice diplomacy and conflict management skills, and polish their twenty-first century competencies and soft skills set while at the same time developing resiliency toward challenges. This research, however, is qualitative action research in nature and is not aimed for generalization to a greater population. Researchers, however, are welcomed to adapt and replicate the design, steps, or techniques applied in the challengebased instructional design to be translated to their own work. Therefore, this research warrants further studies that could be carried out either quantitatively or qualitatively in nature, on ways to improve the learning design or how the learning design has impacted learners in different contexts or cultures. This is in line with the spirit of scholarship of teaching and learning within action research that is reflective and cyclical in nature-doing actions and always looking for rooms for improvements through revisions and reflections (Maree 2007; Ryan 2013). However, I hope that by sharing this research, I will be able to contribute to the body of knowledge by bridging the gap between theory and practice, especially in observing IDC theory in action within the Malaysian context, as well as to the scholarship of teaching and learning.

Acknowledgments

Not applicable.

\section{Author's contribution}

This manuscript is written by a single author. MN prepared and planned this study as a scholarly practice in teaching and learning. This study was meant for her to improvise her teaching and pedagogy qualities as an instructor through action research that was implemented within her own classroom as a continuous quality improvement measures, as well as share it with the public for inspiration and adaptation. The author read and approved the final manuscript.

Authors' information

Mas Nida is a senior lecturer in Instructional Technology and Innovation at the Department of Foundations of Education, Faculty of Educational Studies. Her research interest and specialization include instructional design, innovation, and emerging technologies in teaching and learning, gamification, alternative assessment, and the scholarship of teaching and learning. She is currently the Associate Member of the prestigious Asia-Pacific Society for Computers in Education (APSCE) and is actively involved in the Special Interest Group: Development of ICT in the Asia Pacific Region under the APSCE flagship conference- - the International Conference on Computers in Education, since 2014. At the university level, she is appointed as the Innovation Coordinator under Putra Science Park, as well as the Fellow of Innovation in Teaching and Learning and the Task Force member of Innovative Teaching and Learning under the Center for Academic Development (CADe). Mas Nida has actively participated and won several medals at innovative teaching and learning competitions at both the university and national level. She also has been chairing the Innovation Showcase programme since 2015. Mas Nida is currently the head of the Educational Technology Unit and also the Task Force member of Putra Future Classroom which promotes Technology Enhanced Talaqqi.

Funding

This work was not financially support by any initiative. 


\section{Competing interests}

The author declares that he/she has no competing interests.

Received: 30 July 2019 Accepted: 30 October 2019

Published online: 25 November 2019

\section{References}

Apple Inc. (2010). Challenge based learning: a classroom guide. Retrieved from https://images.apple.com/education/docs/ CBL_Classroom_Guide_Jan_2011.pdf

Balaji, K. V. A., \& Somashekar, P. (2009). A Comparative Study of Soft Skills among Engineers. The IUP Journal of Soft Skills, 3(3), 50-57.

Carr, R., Palmer, S., \& Hagel, P. (2015). Active learning: the importance of developing a comprehensive measure. Active Learning in Higher Education, 16, 173-186.

Chan, T. W., Looi, C. K., Chen, W., Wong, L. H., Chang, B., Liao, C. C. Y., Cheng, H., Chen, Z., Liu, C. C., Kong, S. C., Jeong, H., Mason, J., So, H. J., Murthy, S., Yu, F. Y., Wong, S. L., King, R. B., Gu, X., Wang, M., Wu, L., Huang, R., Lam, R., \& Ogata, H. (2018). Interest-driven creator theory: towards a theory of learning design for Asia in the twenty-first century. Journal of Computers in Education, 5(4), 435-461.

Charmaz, K. (2015). Constructing grounded theory (2nd ed.). London: Sage.

Cross, K. P. (1986). A proposal to improve teching or what "taking teaching seriously" should mean. AAHE Bulletin, 39(1), 9-14.

Denzin, N. K., \& Lincoln, Y. S. (2017). The Discipline and Practice of Qualitative Research. In N. K. Denzin \& Y. S. Lincoln (Eds.), The Sage handbook of qualitative research (5th ed.). Thousand Oaks: Sage.

England Deparment for Education (2011). Teachers' Standards Guidance for school leaders, school staff and governing bodies. England. Retrieved from https://www.gov.uk/government/publications/teachers-standards

Epstein, M., Atkins, M., Cullinan, D., Kutash, K., \& Weaver, R. (2008). Reducing behavior problems in the elementary school classroom: A practice guide. Washington, DC: National Center for Education Evaluation and Regional Assistance, Institute of Education Sciences, U.S. Department of Education.

Fern, E. (1982). The use of focus groups for idea generation: The effects of group size, acquaintanceship, and moderator on response quality and quality. Journal of Marketing Research, 19, 1-13.

Freeman, S., Eddy, S. L., McDonough, M., Smith, M. K., Okoroafor, N., Jordt, H., \& Wenderoth, M. P. (2014). Active learning increases student performance in science, engineering, and mathematics. Proceedings of the National Academy of Sciences USA, 111, 8410-8415.

Glaser, B., \& Strauss, A. (1967). The Discovery of Grounded Theory: Strategies for Qualitative Research. Mill Valley, CA: Sociology Press.

Hennink, M. M. (2014). Focus Group Discussion: Understanding Qualitative Research. New York: Oxford University Press.

Johnson, L. F., Smith, R. S., Smythe, J. T., \& Varon, R. K. (2009). Challenge-based learning: an approach for our time. Austin: The New Media Consortium.

Kemmis, K., \& McTaggart, R. (2000). Participatory Action Research. In N. Denzin \& Y. Lincoln (Eds.), Handbook of Qualitative Research. London: Sage.

Koshy, V. (2005). Action Research for Improving Practice: A Practical Guide. London: Paul Chapman Publishing.

Maree, K. (2007). First steps in research. Pretoria, South Africa: Van Scha ik Publishers.

Ministry of Education Malaysia (2015). Executive Summary Malaysia Education Blueprint 2015-2025 (Higher Education). Retrieved from www.moe.gov.my

Ministry of Education Malaysia (2019). Education Mandate: Education for All. Retrieved from www.moe.gov.my

Moylan, W. A. (2008). Learning by Project: Developing Essential 21st Century Skills Using Student Team Projects. International Journal of Learning., 15(9), 287-292.

Poth, R. D. (2019, April 12). Leveraging Technology to Enhance the Learning Experience. Retrieved from https://www. definedstem.com/blog/leveraging-technology-in-the-classroom/

Ryan, T. G. (2013). The scholarship of teaching and learning within action research: promise and possibilities. I.E. Inquiry in Education, 4(2), 1-18.

Universiti Putra Malaysia (2014). UPM Strategic Plan 2014-2020 (2014). Retrieved from https://coscomm.upm.edu.my/upload/ dokumen/PPSK_1_Buku_Pelan_Strategik_UPM_2014-2020.pdf

Wilhelm, J. D., \& Wilhelm, P. J. (2010, May). Inquiring minds learn to read, write, and think: Reaching all learners through inquiry. Middle School Journal, 41(5), 39-46 Retrieved from http://www.nmsa.org.

Yang, Z., Zhou, Y., Chung, J. W. Y., Tang, Q., Jiang, L., \& Wong, T. K. S. (2018). Challenge based learning nurtures creative thinking: an evaluative study. Nurse Education Today, $71,40-47$.

\section{Publisher's Note}

Springer Nature remains neutral with regard to jurisdictional claims in published maps and institutional affiliations. 